\section{Effectiveness of Periodontal Files}

by

\author{
SHERRY Wells BurKe, R.D.H., M.D.H. \\ EDWARD GREEN, D.D.S., M.S.
}

A VARIETY OF PERIODONTAL FILES have been designed and manufactured, but the effectiveness of specific files in smoothing root surfaces has not been ascertained. The Orban files* and the Bunting files** are representative examples of periodontal file designs presently available. The Bunting files, recommended as being useful in removing fine granules of calculus, were adapted from the set of wide angle files designed by D. D. Smith. ${ }^{1}$ The Orban files were designed more recently and include features intended to diminish the degree of tooth surface roughness resulting from their use. ${ }^{2}$ The roughness of tooth surfaces filed with these instruments was used in this study to compare the smoothing effectiveness of the different file designs.

\section{Methods AND Materials}

Forty-eight freshly extracted human teeth (four from each of 12 patients) were used in this study. Within six hours after extraction, 25 filing strokes were completed with specific files on the mesial and on the distal root surfaces of two of the teeth in each set of four. When a Bunting file (\#15, \#16) was used on the mesial surface of a tooth, an Orban file $(\# 10, \# 11)$ was used on the distal surface and vice versa. The other two teeth in each set of four were used to study the effect of final root planing with a curette (Bunting \#5, \#6) after initial filing. A rotation in the order of the use of instruments was followed, so that within each set of four teeth each type of file was used alone as well as followed by 25 root planing strokes with a curette. The surface roughness was evaluated using the Profilometer*** in a technique previously described, ${ }^{3-5}$ and a roughness score was determined for each instrumented surface. A mean roughness value for each mode of instrumentation was calculated from the individual scores and analysis of variance procedures were used to evaluate the data.

\section{RESULTS}

The findings are summarized in Table 1. Analysis of the scores did not indicate any significant difference in the roughness of the root surfaces after instrumentation

The University of Michigan, School of Dentistry, Ann Arbor, Michigan.

${ }^{*}$ Hu-Friedy Mfg. Co., Inc., Chicago, Illinois.

**S. S. White Mfg. Co., Philadelphia, Pennsylvania.

***Manufactured by the Micrometrical Mfg. Co., Ann Arbor, Michigan.
TABLE 1

Roughness Values

\begin{tabular}{lrl}
\hline Instrumentation & Mean & S.E. \\
\hline Orban files & 9.48 & .474 \\
Bunting files & 10.56 & .572 \\
Orban files plus & 7.79 & .406 \\
$\begin{array}{c}\text { curettes } \\
\text { Bunting files plus } \\
\text { curettes }\end{array}$ & 8.85 & .482 \\
\hline
\end{tabular}

TABLE 2

Variance Between Files Alone, and Files Plus Curettes

\begin{tabular}{lrrrrr}
\hline \multicolumn{1}{c}{ Source } & $\begin{array}{c}\text { Sum of } \\
\text { Squares }\end{array}$ & d.f. & $\begin{array}{c}\text { Mean } \\
\text { Square }\end{array}$ & F ratio & $p$ \\
\hline Between groups & 69.343 & 1 & 69.343 & 11.817 & .001 \\
Within groups & 551.595 & 94 & 5.868 & & \\
\hline
\end{tabular}

with either Orban or Bunting periodontal files. However, as indicated in Table 2, final root planing with a curette after initial use of either file resulted in root surfaces which were significantly less rough $(p<.001)$ than surfaces which were only filed. Half of the samples were root planed using sharp curettes. No significant difference in roughness was indicated between these surfaces and the surfaces which were root planed with curettes which were not sharp.

\section{Discussion}

Apparent differences in the design of the Orban and the Bunting periodontal files include: the size and shape of the working head of the file; the size, shape and angulation of the cutting blades; and the size and shape of the instrument handles (Fig. 1). The working end of the Bunting file has an elongated rectangular shape. It is slightly rounded at its apical end and consists of 20 to 21 relatively fine blades. The lateral corners of the Bunting file blades are sharp and parallel in alignment. A standard octagonal cone socket handle approximately $6 \mathrm{~mm}$ in diameter is used as the handle of the Bunting instruments. The working head of the Orban file has an oval shape and consists of only 5 or 6 cutting blades. The head is shorter in length and is wider at its widest point than the working head of the Bunting files. The corners of the Orban file blades are rounded and the blades are cut at an angle of $105^{\circ}$ with the instrument shank (the blades in the Bunting file are cut at an angle of $90^{\circ}$ ). Also a larger lip angle is used on the Orban file blades.

The diminished heel on the Orban file and the flattened working tip are intended to aid in attempts to reach further into pockets while maintaining adaptation of the instrument to the surface of the tooth. ${ }^{2}$ This investigation provided optimal conditions for use of the files, and did not permit any evaluation of this clinical 


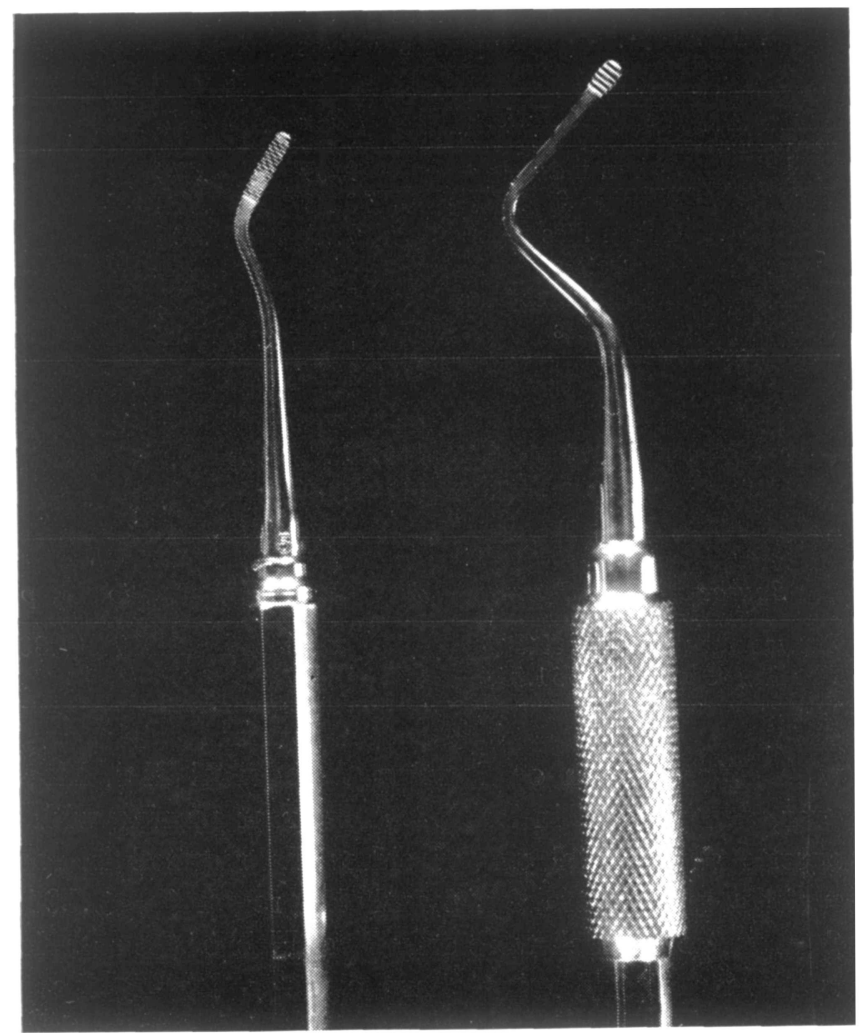

FIGURE 1. Left: Bunting periodontal file; right: Orban periodontal file.

aspect of the Orban file design. Although no significant difference in the effect of the different files on surface roughness was indicated in this study, it is also possible that the findings could have been influenced by the differences in the metal alloys used by the manufacturers in construction of the files tested.

Bunting felt that increased bulk in an instrument handle decreased tactile sense. ${ }^{1}$ The Orban file, however, has an enlarged handle which the designer advocated to eliminate fatigue during instrumentation. ${ }^{2}$ The principal investigator performed all of the instrumentation and found the larger handle more comfortable to use during the extended periods of instrumentation required for this study.

Most studies indicate that the file should not be used as a finishing periodontal instrument. ${ }^{4,6-10}$ In this investigation, smoother root surfaces (lower mean roughness values) resulted when the initial filing instrumentation with either file was followed by final root smoothing with curettes. Half of the root planing was accomplished with dull curettes and half was accomplished with sharp curettes. Although no difference was determined in the results achieved with either the dull or sharp curettes, more pressure was required during instrumentation when the dull curettes were used for final root planing.

\section{SUMMARY}

The purpose of this study was to compare the effects of the Orban and Bunting periodontal files on root surface roughness. A total of 48 freshly extracted human teeth from 12 patients were examined after filing alone and filing followed by root planing with dull and sharp curettes. A standard number of strokes (25) were accomplished on the extracted teeth, and a "profilometer" was used to evaluate (in microinches) the resulting root surface roughness. A statistical analysis of the data was completed and the results indicated that both types of periodontal files produced root surfaces of near equal roughness. A significantly lower surface roughness was produced when the initial use of either of the files was followed by root planing using curettes. No significant difference between the use of a dull or a sharp curette as a final root planing instrument was indicated.

\section{REFERENCES}

1. Bunting, R. W.: Oral Hygiene, ed. 3. Philadelphia, Lea and Febiger, 1957, p. 246-7. 334 p.

2. Orban, B. and Manella, V. B.: A Macroscopic and Microscopic Study of Instruments Designed for Root Planing. J. Periodont., 27:120-35, 1956.

3. Green, E.: Root Planing with Dull and Sharp Curettes. J. Periodont., 39:348-50, 1968.

4. Green, E. and Ramfjord, S. P.: Tooth Roughness After Subgingival Root Planing. J. Periodont., 37:396-99, 1966.

5. Kerry, G. J.: Roughness of Root Surfaces After Use of Ultrasonic Instruments and Hand Curettes. J. Periodont., 38:340-46, 1967.

6. Barnes, J. W. and Schaffer, E. M.: Subgingival Root Planing: A Comparison Using Files, Hoes, and Curettes. J. Periodont., 31:300-3, 1960.

7. Braum, S. T.: The Radicular Surfaces of Teeth Following the Use of Curettes, Hoes, and Files. Ann Arbor, University of Michigan School of Dentistry, 1961 (thesis).

8. Thebaud, Jules: Some Microscopic Aspects of the Curetted Surface of the Cementum After Subgingival $\mathrm{Cu}$ rettage. J. Canad. Dent. Assoc., 17:127-30, 1951.

9. Waerhaug, J., Arno, A. and Lovdal, A.: The Dimensions of Instruments for Removal of Subgingival Calculus. J. Periodont., 25:281-86, 1954.

10. Riffle, A. B.: The Dentin: Its Physical Characteristics During Curettage. J. Periodont., 24:232-41, 1953. 